\title{
Microbial ecotoxicology: an emerging discipline facing contemporary environmental threats
}

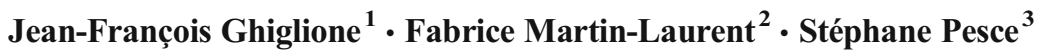

Received: 26 October 2015 / Accepted: 3 November 2015 / Published online: 18 November 2015

(C) Springer-Verlag Berlin Heidelberg 2015

\section{This special issue of ESPR is focused on microbial ecotoxicology. What is 'microbial ecotoxicology'?}

It is a branch of science that studies both (i) the ecological impacts of chemical (synthetic or natural origin) or biological (toxic species) pollution at the microbial scale and on the various functions that they ensure in the ecosystems and (ii) the role of microbial communities in the ecodynamic of the pollutants (source, transfer, degradation, transformation). It is a multidisciplinary scientific endeavor at the crossroad between microbial ecology, microbial toxicology, physics and chemistry (Fig. 1). It responds to an increasing demand worldwide of the politics and society because of the threat on environmental and human health caused by intense anthropogenic activities. In the context of the Anthropocene, microbial ecotoxicology seeks not only to conduct fundamental researches to understand the impact of pollutants on microbial processes and vice versa but also to carry out applied researches to provide tools readily usable by the society to monitor the evolution of the quality of the environment and to restore polluted sites.

Responsible editor: Philippe Garrigues

Jean-François Ghiglione

ghiglione@obs-banyuls.fr

1 Sorbonne Universités, CNRS, UPMC Univ Paris 06, UMR 7621, Laboratoire d'Océanographie Microbienne, Observatoire Océanologique, Banyuls/mer F-66650, France

2 INRA, UMR 1347 Agroécologie, 17 rue Sully, Dijon F-21065, France

3 Irstea, UR MALY, centre de Lyon-Villeurbanne, 5 rue de la Doua-CS 70077, Villeurbanne cedex F-69626, France

\section{Why is it important to consider the microbial biosphere in ecotoxicology?}

The history of microbial ecotoxicology pops up recently (Ghiglione et al. 2014) decades after the emergence of ecotoxicology (Truhaut 1977). Such investigation arose because of tremendous technological breakthroughs in the last decades by applying molecular tools such as next-generation sequencing giving new insight in estimating the abundance, structure and diversity of microbial community in complex environments (Tautz et al. 2010, Ghiglione et al. 2012). Because microbial ecologists demonstrated that microbial life is very diverse and plays a primary role in supporting various ecosystem functions in virtually all of our planet's environments (Barton and Northup 2011), microbial ecotoxicologists go beyond the restricted use of model organisms generally used in toxicology, preferentially performing investigations at community level. This statement is nicely illustrated by the word cloud generated from title words and keywords in this special issue (Fig. 2). Microbial ecotoxicology paves the way to assess the impacts of contaminants on taxonomic and functional microbial biodiversity which is supporting ecosystem functions and ensuring their stability and recovery. This is in accordance with the need to reinforce the ecological relevance of ecotoxicological studies (SchmittJansen et al. 2008) in order to provide new ecological indicators and give new insight in measuring the impact of pollutants on 'ecosystem health' (Costanza et al. 1992).

Possibly, one of the originality of microbial ecotoxicology lies in the role of microorganisms in the ecodynamic of the pollutants, which is not strictly taken into account in ecotoxicology. Microbial contamination can occur by accidental introduction of infectious microorganisms (bacteria, yeast, mould, fungi, virus, prions, protozoa) or their 


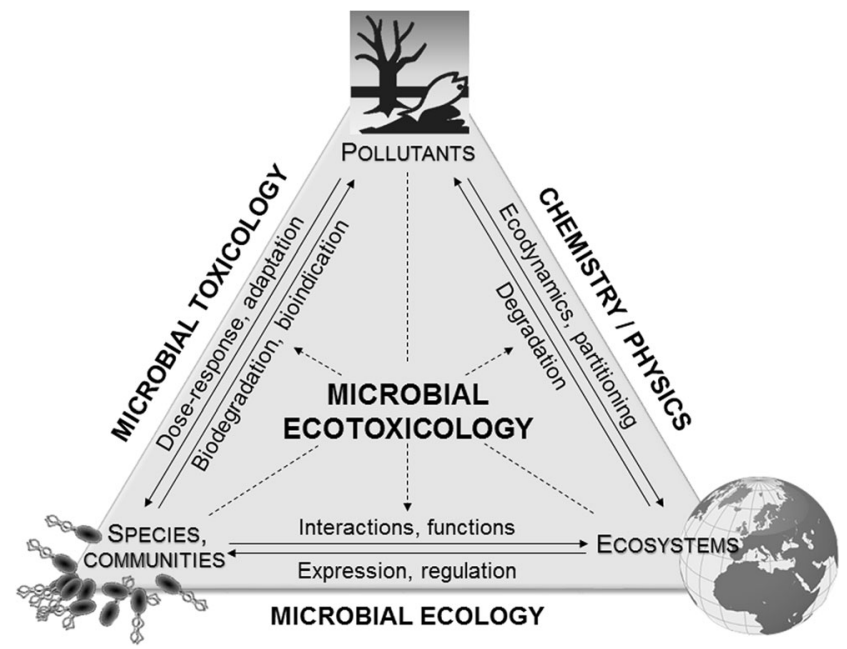

Fig. 1 Microbial ecotoxicology is a multidisciplinary science at the crossroad between microbial ecology, microbial toxicology, physics and chemistry

toxins and by-products in the environment (Proft 2009). Inversely, microorganisms present the capability to cope with chemical and/or biological contaminants to restore polluted sites. Bioremediation uses mainly microorganisms to clean up contaminated environments, involving biotransformation and biodegradation by transforming contaminants to non-hazardous or less hazardous chemicals (Alexander 1999). Natural communities of microorganisms in various habitats have an amazing physiological versatility, being able to metabolize and often mineralize huge number of molecules.

\section{What are the researches given in this special 'microbial ecotoxicology' issue?}

One can argue that given the green thinking that arose at the end of the last millenary notably following the publication of the Millennium Ecosystem Assessment, the human society tried to adopt environmentally friendly resolutions, reducing the risk of acute and high-volume pollution, at least in Europe and North America. However, despite these constant efforts marked by the succession of international conventions under the United Nations flag, the society is having difficulties to reach international agreements to reduce anthropogenic threats to nature. Consequently, ecosystems are still threatened by low concentrations of a steadily increasing number of pollutants that cause subtle and chronic effects.

This special issue gives a number of examples reporting the broad variety of pollutants that microbial ecotoxicologists are studying: nanoparticles (gold, silver, zinc, titanium, multi-walled carbon nanotubes), metals (copper, ferrous iron, arsenic, lead), antibiotic and antimicrobial ionic liquids, solvent (methanol), high alkaline $(\mathrm{pH}>13$ !), aromatic hydrocarbons (toluene, PAHs), PCBs, pesticides (atrazine, chlordecone, 2,4-D, mesotrione, nicosulfuron, sulcotrione, sulfamethoxazole). The international scientific community that contributed to the special issue proposed works performed on samples originated from a large variety of ecosystems: freshwater, sewage water, drainage water from landfills or from watershed, fluid systems in an automobile industry, lake, groundwater, river, estuarine, seawater, wetland and planted or unplanted soils. As illustrated by the word cloud (Fig. 2), microorganisms of interest were mainly bacteria, fewer on fungi and microalgae, archaea being rarely considered. A majority of articles focused on the impact of pollutants on microbial diversity and functional capabilities, but numerous papers were dedicated to the study of biodegradation processes and the improvement of bioremediation strategies. Relatively few studies presented here were done under culture conditions with only one model species, while most of them were studying the communities as whole or specific functional communities under micro- or mesocosm conditions or in the field. The large broad of technological tools used in each of the articles is also representative of the multidisciplinarity and the high degree of technicality that are needed today for acceptance in international peer review journal.

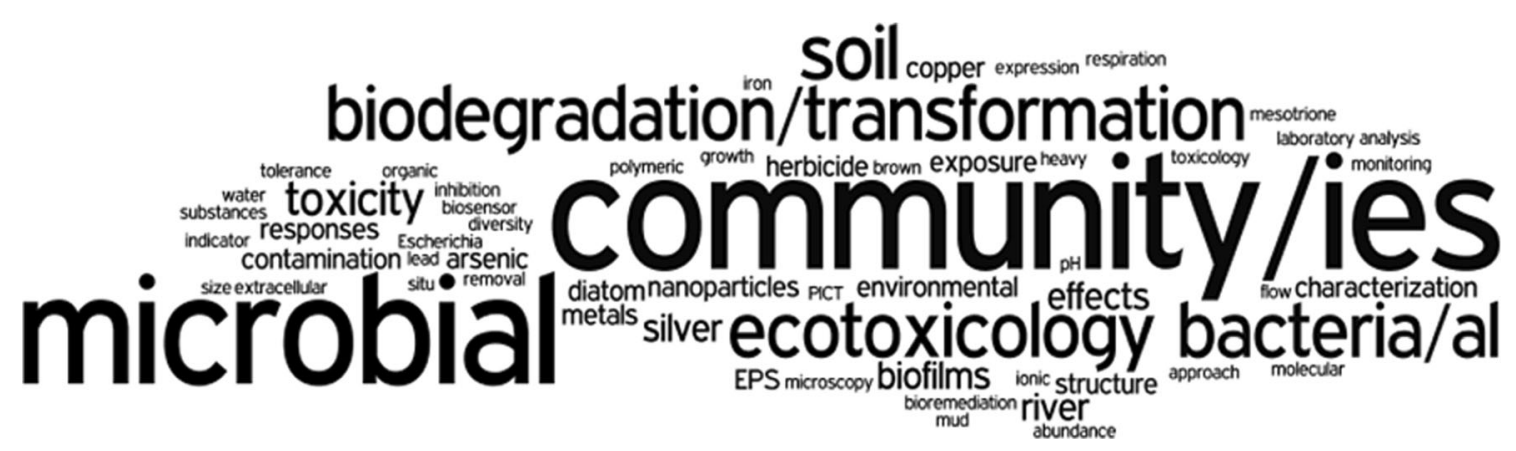

Fig. 2 Word cloud generated by Wordle (http://www.wordle.net/) using the most frequent 60 words in the titles and keywords of the 'microbial ecotoxicology' special issue articles. Words used in both title and keywords were only considered once in the Wordle analysis 
Acknowledgments We are grateful to our colleagues Bernard C, Chapon V, Leboulanger C, Leyval C, Pollet T, Sanchez W, StachowskiHaberkorn $\mathrm{S}$ and Vuillemier $\mathrm{S}$ for their involvement in the directory board of the French pluridisciplinary thematic network (RTP) EcotoxicoMic aiming at promoting microbial ecotoxicology researches in France (http://ecotoxicomic.irstea.fr/rtp-ecotoxicomic/). We are also greatly indebted to P. Garrigues for his support and help since the early stages of development of the EcotoxicoMic Network.

\section{References}

Alexander M (1999) Biodegradation and bioremediation, 2nd edn. Academic Press, London

Barton LL, Northup DE (2011) Microbial ecology. Wiley-Blackwell, Oxford: John Wiley \& Sons, p 440

Costanza R (1992) Toward an operational definition of ecosystem health. pp. 239-256 in Costanza R, Norton B, and Haskell BJ (eds.), Ecosystem health: New Goals for Environmental Management. Island Press, Washington DC, 269 pp.

Ghiglione JF, Galand PE, Pommier T, Pedrós-Alió C, Maas EW, Bakker K, Bertilson S, Kirchman DL, Lovejoy C, Yager PL, Murray AE (2012) Pole to pole biogeography of surface and deep marine bacterial communities. Proc Natl Acad of Sci USA 109:17633-8

Ghiglione JF, Martin-Laurent F, Stachowski-Haberkorn S, Pesce S, Vuilleumier S (2014) The coming of age of microbial ecotoxicology: report on the first two meetings in France. Environ Sci Poll Res 21:14241-14245

Proft T (2009) Microbial toxins: current research and future trends. Caister Academic Press, Norfolk, U.K, pp 147-166

Schmitt-Jansen M, Veit U, Dudel G, Altenburger R (2008) An ecological perspective in aquatic ecotoxicology: approaches and challenges. Basic Appl Ecol 9:337-345

Tautz D, Ellegren H, Weigel D (2010) Next generation molecular ecology. Mol Ecol 19:1-3

Truhaut R (1977) Ecotoxicology: objectives, principles and perspectives. Ecotoxicol Environ Saf 1:151-173

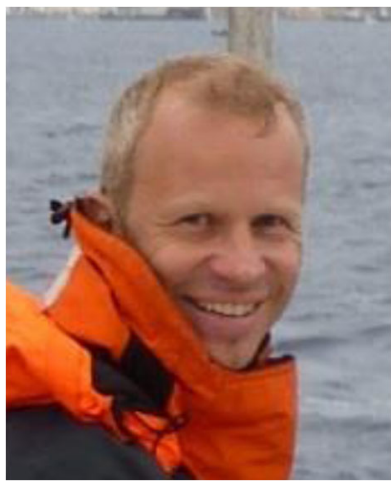

Jean-François Ghiglioneis a CNRS senior scientist at the Laboratory of Microbial Oceanography (LOMIC-UMR7621, Banyuls-surMer, France), where he is leading the research team 'marine microbial ecotoxicology and engineering'. He has 15-year research experience in marine microbial ecotoxicology with particular expertise on microbial diversity, microbial ecology, biogeochemistry and biodegradation of persistent organic pollutants (POPs). His current research focuses on the colonization and biodegradation of marine plastic litters. Relevant recent discoveries include the characterization of global biogeography of marine bacteria on Earth, the importance of the 'rare biosphere' in the POPs degradation by bacteria and the relative role of the bottom-up and top-down controls to improve bioremediation strategies. Since 2012, he is a board member of the francophone association for microbial ecology (http://mio.pytheas.univ-amu.fr/AFEM/). $\mathrm{He}$ is a member of the scientific council of CNRS-INSU since 2014 (http:// www.cnrs.fr/comitenational/csi/insu.htm). Since 2015, he is the chair of the French pluridisciplinary thematic network (RTP) on microbial ecotoxicology (http://ecotoxicomic.irstea.fr/rtp-ecotoxicomic/).

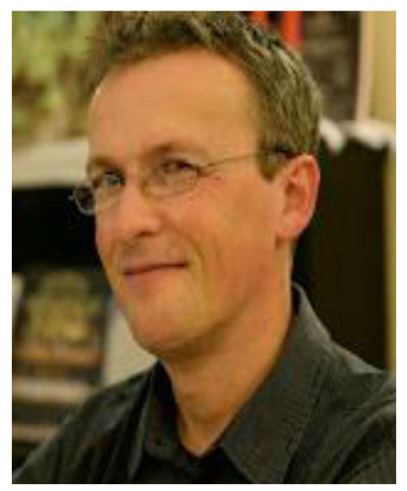

Fabrice Martin-Laurent is a senior scientist at the National Institute for Agricultural Research (INRA) in the Agroecology research unit in Dijon, France. He is leading a research team studying functional microbial ecology of agricultural chemicals including fertilizers and pesticides. His main research interest is focused on pesticide microbial ecotoxicology. On one hand, he is developing innovative molecular approaches to assess the impact of pesticide residues on the composition, abundance, diversity and activity of soil microbial community. On the other hand, he is studying the adaptation processes responsible for the selection of soil microorganisms able to rapidly biodegrade pesticides. Fabrice Martin-Laurent is co-leading the INRA's national network of Ecotoxicologists, ECOTOX (http://www6.inra.fr/ecotox), is the co-creator of the French Network of Microbial Ecotoxicology (http://ecotoxicomic.irstea.fr/) and is a member of advisory board of the French pluridisciplinary thematic network (RTP) on microbial ecotoxicology (http://ecotoxicomic.irstea.fr/rtp-ecotoxicomic/).

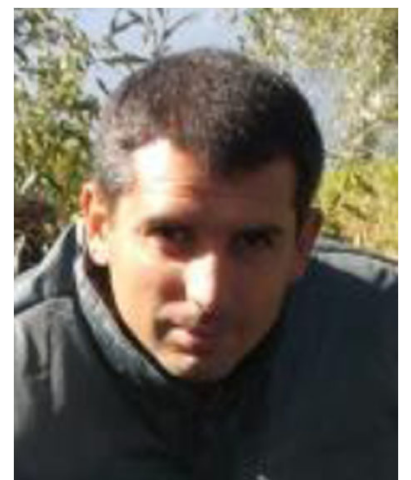

Stéphane Pesce is a mid-level scientist at the National Research Institute of Science and Technology for Environment and Agriculture (Irstea) in the 'Freshwater Systems, Ecology and Pollution' research unit in Lyon-Villeurbanne, France. $\mathrm{He}$ is leading the team 'microbial ecology in anthropized hydrosystem' studying the structural and functional responses of aquatic phototrophic and heterotrophic microbial communities to varying levels of exposure to organic and inorganic toxicants. Investigations are performed on periphytic biofilm, sediment and leaf litter microbial communities, and a special attention is given to the study of microbial adaptation processes following chronic exposure to toxicants (pollution-induced community tolerance, stimulation of biodegradation capacities...). He is the co-creator of the French Network of Microbial Ecotoxicology (http://ecotoxicomic.irstea.fr/) and is a member of advisory board of the French pluridisciplinary thematic network (RTP) on microbial ecotoxicology (http://ecotoxicomic.irstea.fr/rtp-ecotoxicomic/). Since 2015, he is a member of the Directory Board of the Rovaltain Scientific Foundation for research in Health and Environment (http://www.fcsrovaltain.org/). 